OPEN ACCESS

Edited by:

Frederik Hammes,

Swiss Federal Institute of Aquatic Science and Technology, Switzerland

Reviewed by:

Ruben Props,

Ghent University, Belgium

Naresh Singhal,

The University of Auckland,

New Zealand

Emily Garner,

Virginia Tech, United States

*Correspondence:

Marija Zunabovic-Pichler marija.zunabovic@boku.ac.at

Specialty section:

This article was submitted to Microbiotechnology, Ecotoxicology

and Bioremediation,

a section of the journal

Frontiers in Microbiology

Received: 14 August 2018 Accepted: 12 November 2018

Published: 29 November 2018

Citation:

Fiedler CJ, Schönher C, Proksch P, Kerschbaumer DJ, Mayr E, Zunabovic-Pichler M, Domig KJ and Perfler R (2018) Assessment of Microbial Community Dynamics

in River Bank Filtrate Using

High-Throughput Sequencing and Flow Cytometry.

Front. Microbiol. 9:2887.

doi: 10.3389/fmicb.2018.02887

\section{Assessment of Microbial Community Dynamics in River Bank Filtrate Using High-Throughput Sequencing and Flow Cytometry}

\author{
Christina J. Fiedler', Christoph Schönher', Philipp Proksch', \\ David Johannes Kerschbaumer ${ }^{1}$, Ernest Mayr', Marija Zunabovic-Pichler ${ }^{1 *}$, \\ Konrad J. Domig ${ }^{2}$ and Reinhard Perfler ${ }^{1}$
}

\footnotetext{
${ }^{1}$ Laboratory of Microbiology, Institute of Sanitary Engineering and Water Pollution Control (SIG), Department of Water, Atmosphere and Environment, University of Natural Resources and Life Sciences, Vienna, Austria, ${ }^{2}$ Laboratory of Food Microbiology and Hygiene, Institute of Food Science, Department of Food Science and Technology, University of Natural Resources and Life Sciences, Vienna, Austria
}

Surface-groundwater interactions play an important role in microbial community compositions of river bank filtrates. Surface water contaminations deriving from environmental influences are attenuated by biogeochemical processes in the hyporheic zone, which are essential for providing clean and high-quality drinking water in abstraction wells. Characterizing the flow regime of surface water into the groundwater body can provide substantial information on water quality, but complex hydraulic dynamics make predictions difficult. Thus, a bottom up approach using microbial community shifting patterns as an overall outcome of dynamic water characteristics could provide more detailed information on the influences that affect groundwater quality. The combination of high-throughput sequencing data together with flow cytometric measurements of total cell counts reveals absolute abundances among taxa, thus enhancing interpretation of bacterial dynamics. 16S rRNA high-throughput sequencing of 55 samples among six wells in a well field in Austria that is influenced by river bank filtrate within a time period of 3 months has revealed both, clear differences as well as strong similarity in microbiome compositions between wells and dates. A significant community shift from April to May occurred in four of six wells, suggesting that surface water flow regimes do affect these wells stronger than others. Triplicate sampling and subsequent sequencing of wells at different dates proved the method to be reproducible. Flow cytometric measurements of total cells indicate microbial shifts due to increased cell counts and emphasize the rise of allochthonous microorganisms. Typical freshwater bacterial lineages (Verrucomicrobia, Bacteroidetes, Actinobacteria, Cyanobacteria, Armatimonadetes) were identified as most increasing phyla during community shifts. The changes are most likely a result of increased water abstraction in the wells together with constant river water levels rather than rain events. 
The results provide important knowledge for future implementations of well utilization in dependency of the nearby Danube River water levels and can help drawing conclusions about the influence of surface water in the groundwater such that hygienically save and clean drinking water with a stable microbial community can be provided.

Keywords: high-throughput sequencing, next generation sequencing (NGS), microbial community composition, drinking water quality, bank filtration, groundwater, absolute abundance, flow cytometry

\section{INTRODUCTION}

Groundwater provides a vast reservoir for drinking water and contributes to the drinking water supply of $1.5-3$ billion people worldwide (Katsanou and Karapanagioti, 2017). Its functioning is dependent on a versatile ecosystem that maintains clean and hygienically safe water via self-purification processes, implemented by diverse autochthonous microbial communities (Danielopol et al., 2003; Griebler et al., 2014). In order to protect this irreplaceable ecosystem, national as well as international strategies are developed to prevent pristine aquifers from vast anthropogenic impacts, possibly leading to permanent microbial turnover and thus resulting in degradation of water quality (Getches, 1989; Bredenhann and Braune, 2000; European Commission, 2000). Nevertheless, the definition of good groundwater quality only depends on physicochemical parameters, but excludes microbiological characteristics (European Commission, 2000).

Groundwater ecosystems are characterized by oligotrophic environments containing highly adapted microorganisms due to low nutrient availability and further abiotic factors (Karczewski et al., 2017). As a consequence, the total number of microorganisms in groundwater is $10-100$ times lower as compared to surface water (Pedersen, 2000; Griebler and Lueders, 2009) with a large proportion belonging to the viable but non-culturable (VBNC) organisms (Roszak and Colwell, 1987). The vast majority of bacteria contributing to pristine water communities has not been cultured yet, thus bacterial physiology among them and metabolic community functioning remain widely unknown (Rappé and Giovannoni, 2003; Raes and Bork, 2008). Therefore, the investigation of changes among communities rather than the characterization of single samples can provide insights into adaptations of microbial communities to biotic as well as abiotic factors, such as temperature, turbidity, $\mathrm{pH}$, dissolved oxygen, total and dissolved organic carbon and ammonia (Kaevska et al., 2016; Hou et al., 2018; Liao et al., 2018).

The influences that contaminations can have on microbial communities have been thoroughly studied (Li et al., 2017; Zhang Y. et al., 2017; Romera-Castillo et al., 2018; Wang et al., 2018), but knowledge on commonly occurring impacts investigated by microbial community analyses remain scarce (Pronk et al., 2009; Schwab et al., 2017).

Wells serving as drinking water resources in the vicinity of rivers are influenced by river bank filtration. Especially the hyporheic zone between surface water and groundwater provides living space for a variety of microorganisms and biological activity within this zone contributes to the natural attenuation of contaminants from surface water infiltrating into the aquifer, usually resulting in minor changes in the biogeochemical processes of the reservoirs (Boulton et al., 1998; Hiscock and Grischek, 2002). Although persistence of allochthonous microorganisms in the groundwater bodies is unlikely (Pronk et al., 2009), river bank filtration systems are considered to be vulnerable to extreme weather conditions such as floods and droughts (Sprenger et al., 2011; Besmer et al., 2017). Increased water level differences between river and wells due to season and rain events as well as increased pumping rates at well sites shorten interstitial residence time of water and reduce bank filtration processes, resulting in increased entry of allochthonous microorganisms in the groundwater body (Sprenger et al., 2011).

Investigating microbial differences between wells can indicate the degree of surface water influence among them (Lin et al., 2012). With such information at hand, conclusions can be drawn on distribution patterns of surface water within the well field as well as the period of the autochthonous microbial community to recover from allochthonous impacts. Furthermore, the detection of certain microbial groups can indicate both hygienic contamination as well as technical issues that may arise within the subsequent water treatment and distribution processes (Ascott et al., 2016).

So far, both, models and on-site investigations have been made to draw conclusions about impacts of surface water on the groundwater body and biological as well as physico-chemical parameters have been investigated within them (Ray et al., 2002; Wett et al., 2002; Ascott et al., 2016). Nevertheless, how entire microbial communities actually respond to events influencing bank filtration processes and how the distribution patterns of surface water in a well field can influence them, still needs to be investigated.

Within the last two decades, the development of highthroughput sequencing techniques has substantially increased our understanding of microbial population diversities in the environment and allows for the accurate identification of microbial taxa (van Dijk et al., 2014). However, the massively parallel sequencing techniques of hypervariable regions of $16 S$ rRNA genes are associated with several biases that are partially overcome by optimized extraction methods, increased sequencing depth, improved bioinformatic tools, choice of primers as well as the use of replicates (Robasky et al., 2014; Hugerth and Andersson, 2017). So far, replicates have been used for DNA extraction and PCR amplification, respectively (Vivien et al., 2016; Ge and Yu, 2017), but samples were almost exclusively pooled prior to sequencing, thus making comprehensive evaluations of replicates impossible (Staley et al., 2015).

The application of flow cytometry for cell counting in water provides a useful tool to quantify entire bacterial communities 
(Van Nevel et al., 2017). Due to high sampling frequencies and rapid processing, short-term microbial dynamics, e.g., after precipitation events can be detected. The combined use of total cell counts together with sequencing data provides samplespecific estimated absolute taxon abundances (EAA). Due to the identification of real abundance changes, EAAs tend to be more informative regarding community population dynamics rather than relative abundances without absolute quantification (Zhang Z. et al., 2017). The goal of this study was to compare microbial communities within six wells that are characterized by river bank filtration. The investigation period included two seasons, winter and spring and covers water level differences between surface water and groundwater as well as a flood event. Using high-throughput $16 \mathrm{~S}$ rRNA sequencing methods, microbial community compositions were investigated. Triplicate sampling was performed in order to assess reproducibility of the method. Spatial and temporal variation in microbial communities provide a basis for predicting both hygienically relevant as well as technical aspects of drinking water catchment.

\section{MATERIALS AND METHODS}

\section{Study Site and Sample Collection}

The well field of sampling is located next to an intermittently donated backwater (alluvial part of the river with little current), at approximately $300 \mathrm{~m}$ distance from the Danube River, situated in the Donau-Auen National Park, Austria (Figure 1). Wells 1 4 and 6 are about equidistant from water $(30-37 \mathrm{~m})$, well 5 is $65 \mathrm{~m}$ away from water. A total of 55 samples from 6 different wells were taken. Samples were taken five times within 4 months, from February to May 2017. 15 samples at three different dates were taken as triplicates, as well as 10 single samples (depending on available resources). A sample volume of $5 \mathrm{~L}$ was taken in glass bottles covered with aluminum foil and muffled at $550^{\circ} \mathrm{C}$ for $5 \mathrm{~h}$. For cell counting, $50 \mathrm{ml}$ were additionally sampled in sterile centrifuge tubes (VWR, United States). Additional parameters were measured on-site (temperature, electrical conductivity, redox potential, water levels and abstraction rates in the wells). Sampling taps were thoroughly flamed and water was flushed for $10 \mathrm{~min}$ before sampling. Samples were transported and stored at $4^{\circ} \mathrm{C}$ and processed within $24 \mathrm{~h}$.

\section{Filtration}

Samples were filtered through sterile $0.2 \mu \mathrm{m}$ PES membrane filters (47 mm Supor 200, Pall, MI, United States) using a water jet pump, rolled up using sterile forceps and transferred into collection tubes from the subsequently used extraction kit. Membrane filters were stored at $-80^{\circ} \mathrm{C}$ until DNA extraction.

\section{Total Cell Count}

The count of total cells was measured by fluorometric staining of nucleic acids and subsequent detection of cells with a flow cytometer based on the Austrian protocol (Zunabovic-Pichler et al., 2018). $297 \mu \mathrm{l}$ of well mixed sample were stained with $3 \mu \mathrm{l}$ SYBR ${ }^{\circledR}$ Green I (Life Technologies, Eugene, OR, United States), previously diluted 1:100 with DMSO (Fluka, Switzerland) and subsequently incubated in the dark for $13 \mathrm{~min}$. Flow cytometric measurements were performed using a BD Accuri C6 flow cytometer (BD Life Sciences, CA, United States) containing a $50 \mathrm{~mW}$ laser emitting at a wavelength of $488 \mathrm{~nm}$. The contained volumetric counting hardware was set to measure the number of particles in $50 \mu \mathrm{l}$, which is subsequently calculated to a volume of $1 \mathrm{ml}$. Measurements were implemented three times at a flow rate of $35 \mu \mathrm{l} / \mathrm{min}$. Obtained data were processed using the $\mathrm{R}$ package flowCore. The bacterial signal was differentiated from background noise by electronic gating (Supplementary Figure 1).

\section{DNA Extraction}

DNA was extracted from the filters using the DNeasy PowerWater Kit (Qiagen, Germany) following the protocol, with some modifications: Bead beating was extended to $10 \mathrm{~min}$, followed by $4 \mathrm{~min}$ centrifugation at $4,000 \mathrm{~g}$. The incubation time at $4^{\circ} \mathrm{C}$ after addition of inhibitor removal solution (IRS) was extended to $10 \mathrm{~min}$. DNA was eluted in $50 \mu \mathrm{l}$ elution buffer. Subsequently, DNA concentration was measured on a Qubit 2.0 fluorometer using a Qubit ${ }^{\circledR} \mathrm{dsDNA}$ HS Assay Kit (Invitrogen, OR, United States) following manufacturer instructions. $1 \mu \mathrm{l}$ DNA was added to $199 \mu \mathrm{l}$ working solution for measurement. Genomic DNA as well as all further DNA products were stored at $-20^{\circ} \mathrm{C}$ until processing.

\section{PCR Amplification and Sequencing}

A two-step PCR barcoding approach was used as suggested by Herbold et al. (2015). For the first PCR reaction, generating the $16 \mathrm{~S}$ amplicon products, the universal primers S-D-Bact-0341-bS-17 (5'-CCT ACG GGN GGC WGC AG-3') and S-D-Bact-0785a-A-21 (5'-GAC TAC HVG GGT ATC TAA TCC-3'), targeting the hypervariable $\mathrm{V} 3 / \mathrm{V} 4$ region of the $16 \mathrm{~S} \mathrm{rRNA}$ gene were used as described by Klindworth et al. (2013). PCR reactions were implemented using a reaction volume of $26 \mu$ l containing $12.5 \mu \mathrm{l}$ Mastermix (KAPA HiFi Hotstart ready mix, peqlab, Germany), $5 \mu \mathrm{l}$ forward and reverse primer $(2 \mu \mathrm{M})$ each and $3.5 \mu$ l template DNA. The following PCR conditions were used: initial denaturation at $95^{\circ} \mathrm{C}$ for $5 \mathrm{~min}$, followed by $32-37$ cycles of denaturation at $95^{\circ} \mathrm{C}$ for $30 \mathrm{~s}$, annealing at $66^{\circ} \mathrm{C}$ for $30 \mathrm{~s}$ and extension at $72^{\circ} \mathrm{C}$ for $30 \mathrm{~s}$ and a final extension step at $72^{\circ} \mathrm{C}$ for $5 \mathrm{~min}$. The amount of cycles was adjusted to the initial DNA concentrations, ranging from 3.4 to $66.8 \mathrm{ng} / \mu \mathrm{l}$. With each PCR reaction a negative control containing pure water (SigmaAldrich, Switzerland) as template was included to check for contaminations. PCR products were purified using the peqGOLD cycle-pure kit (Safety line, peqlab, Germany) according to manufacturer instructions with the following modifications: The drying step of the column after washing was extended to $5 \mathrm{~min}$, $40 \mu \mathrm{l}$ elution buffer were incubated for $5 \mathrm{~min}$, followed by a $2 \mathrm{~min}$ centrifugation step. After amplification, a gel electrophoresis with a $100 \mathrm{bp}$ ladder was performed on a $2 \%$ agarose gel to verify the size quality of purified PCR products. DNA was quantified using Qubit $^{\circledR}$. Concentrations ranged from 0.71 to $11.0 \mathrm{ng} / \mu \mathrm{l}$.

The second PCR (Index PCR) converts amplicon products into library products for sequencing. It was implemented using Illumina primers from Nextera ${ }^{\circledR} \mathrm{XT}$ index kit v2 (Illumina, CA, 


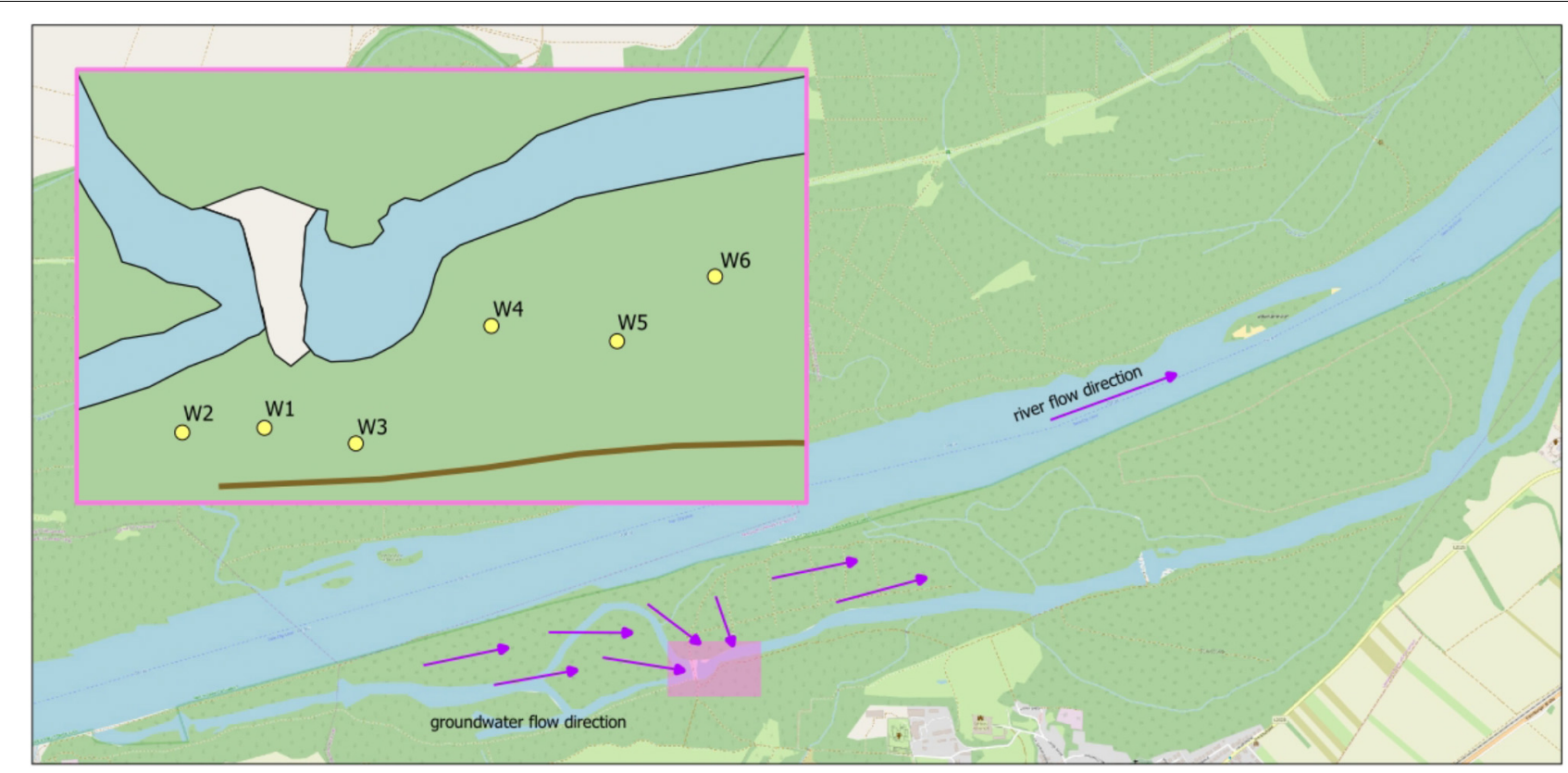

FIGURE 1 | Outline map of the investigated well field. Arrows indicate the flow path. W1-W6, wells 1-6; MW, monitoring well of backwater.

United States) and KAPA HiFi Hotstart ready mix. $5 \mu l$ of one N7xx and one S5xx primer (unique combination for each sample), $25 \mu \mathrm{l}$ mastermix and $15 \mu \mathrm{l}$ amplicon PCR product (normalized to $20 \mathrm{ng}$ using purified water) were processed using the same PCR conditions as before, except of using only seven amplification cycles. Purification, gel electrophoresis and quantification of DNA was implemented as before. DNA concentrations ranged from 8.18 to $33.2 \mathrm{ng} / \mu \mathrm{l}$. All samples were normalized to $12 \mathrm{ng} / \mu \mathrm{l}$ (for concentrations $<12 \mathrm{ng} / \mu \mathrm{l}$ undiluted PCR products were used) using $10 \mathrm{mM}$ TRIS buffer (Sigma-Aldrich, Switzerland) and an aliquot of $5 \mu \mathrm{l}$ was pipetted into the final pool. From this, a gel electrophoresis and a DNA quantification were implemented as a final quality control and the library was sequenced at Microsynth, Switzerland on an Illumina MiSeq platform, using the v3 reaction kit, $2 \times 300 \mathrm{bp}$ for paired-end sequencing. Demultiplexing and trimming of Illumina adaptor residuals, trimming of locus specific adaptors (cutadapt $\mathrm{v}$ 1.8.1) and merging of forward and reverse reads (Usearch $\mathrm{v}$ 8.1.1861) was carried out by Microsynth. Sequence data was received as.fastq files. The dataset can be found in the European Nucleotide Archive (ENA) PRJEB28172.

\section{Data Analysis}

All data processing was performed using the Quantitative Insights into Microbial Ecology 2 (QIIME 2) 2018.4.0 microbiome analysis pipeline ${ }^{1}$ and $\mathrm{R}$ Statistical Software Version 3.44. The $\mathrm{R}$ package phyloseq was used to generate bar charts depicting relative and absolute abundance of taxa (McMurdie and Holmes, 2013). Using the DADA2 pipeline

${ }^{1}$ https://qiime2.org [access 12/06/2018]
(Callahan et al., 2016), quality filtering, denoizing, merging and removal of chimeric sequences was applied on the data set. Taxonomies were assigned to the feature table using the naïve Bayes classifier implemented in QIIME 2 together with the SILVA 132 database (99\% clustering, 7 levels, majority vote). Reads from triplicate samples were pooled for analyses of merged triplicates.

Generated total cell counts from flow cytometric data were multiplied by the relative abundances of taxa to reveal EAA among them as suggested by Props et al. (2017).

Alpha-diversity was investigated using Shannon-diversity index, Pielou's evenness and observed richness parameters. Rarefaction was implemented for alpha-diversity measures. Principle Coordinate Analysis (PCoA) plots were generated from Bray-Curtis distances based on sequence variants to visualize beta diversity. Permutational Multivariate Analysis of Variance (PERMANOVA) based on Bray-Curtis dissimilarities (relative abundances) was performed to test for differences in betadiversity among groups (Anderson, 2008). As implementation of PERMANOVA the function adonis of R-package vegan (Oksanen et al., 2018) was used, the number of permutations was set to 10,000 .

Using the package DAtest (Russel et al., 2018) an optimal procedure for differential abundance testing was identified for both, relative abundances as well as EAAs. In short, DAtest finds well suited methods for the specific dataset at hand by repeated calculation of quality scores based on shuffling predictor variables, random spiking of features corresponding to the shuffled predictor variables and the application of a wide range of available testing methods aiming at identifying the spiked features. After application of DAtest the best scoring testing methods were used to find differentially abundant phyla. 


\section{RESULTS}

\section{Bacterial Diversity}

A total of 13,584,552 past filter reads (sum of forward and reverse reads) with a mean read length of $299 \mathrm{bp}$ and a mean quality score of 31 were retrieved from 55 samples. After processing with QIIME2, library size ranged from 20,658 to 107,485 reads with a mean of 53,068 merged reads per sample ( $43 \%$ reads passing quality filtering). Since the number of reads per sample was considered sufficient for downstream analyses, no relaxation of quality filtering criteria was performed. 34,980 sequence variants were observed and used for downstream taxonomic analyses.

The Shannon alpha-diversity index ranged from 5.08 to 7.35. Observed richness and Pielou's evenness ranged from 1344 to 4537 and 0.65 to 0.92 , respectively. Well 4 represents the highest range between samples for all parameters $(6.34 \pm 0.77$; $2,444 \pm 728$ and $0.82 \pm 0.1$, respectively) (Table 1 ).

\section{Triplicate Similarity}

According to the suggestion of Staley et al. (2015), 15 of the investigated probes were sampled and processed in triplicates in order to compare diversity parameters. Principal coordinate analysis $(\mathrm{PCoA})$ of triplicates showed similarity among triplicates compared to distinctiveness of samples (Figure 2). Shannondiversity and Pielou's evenness show a variation coefficient of $0.028 \pm 0.021$ and $0.010 \pm 0.014$, respectively within triplicates, whereas observed richness shows a higher variation of $0.171 \pm 0.115$ as well as variability in library size (variation coefficient $0.241 \pm 0.163$ ).

\section{Spatial and Temporal Variability}

Well 5 shows to be most stable throughout the investigation period regarding both alpha-diversity (Shannon alpha-diversity index $6.88-7.31)$ as well as total cell counts $\left(1.5 \times 10^{5}-1.8 \times 10^{5}\right.$ cells $/ \mathrm{ml}$ ), whereas well 4 is very variable in both parameters (5.08- 7.03 and $1.3 \times 10^{5}-4.7 \times 10^{5}$ cells $/ \mathrm{ml}$, respectively). Alpha-diversity among wells appears similar from February to April. Between April 4 and April 7, respectively and May 3 differences in diversity become more pronounced.

Based on Bray-Curtis dissimilarity, the dynamics in community compositions of wells $1-3$ behave in a similar way during the investigated period: A major shift occurs from April 7 to May 3, but wells shift in the same direction (Figure 2).
Wells $4-6$ also behave similar to each other with the exception that wells 5 and 6 do not show major shifts from April to May 3 , but rather on May 10, although to a much lesser extent than well 4 (Figure 2). This is in general accordance with the geographical adjacency of wells $1-3$ and $4-6$, respectively (Figure 1), although spatial differences contribute less to the dissimilarity than temporal shift does $[y$-axis of PCoA accounts for only $11.0 \%, x$-axis for $28.1 \%$ of dissimilarity (Figure 2)]. Microbial community changes correlate with the change in total cell counts: From May 3, cell counts increase in wells 1 4, well 6 shows that increase on May 10, but again to a lesser extent, well 5 remains similar (Figure 3). Considering that the most noticeable changes happen from April 7 to May 3 and that triplicate results from all wells exist among those dates, taxonomical identification will mainly focus on the dynamics between the two dates.

\section{Microbial Community Distribution}

56 different phyla were identified, of which the most abundant phyla included Planctomycetes (12.2 - 48.2\%), Omnitrophicaeota (2.6 - 34.1\%), Patescibacteria (4.5 $37.5 \%)$, Acidobacteria $(1.3-17.9 \%)$ and Proteobacteria (2.2 - 16.2\%) contributing to more than $75 \%$ relative abundance among all samples. Temporal dynamics in microbial communities contribute greatly to the variability of relative abundances: The most increasing phyla from April 7 to May 3 are Verrucomicrobia, Actinobacteria, Cyanobacteria, and Bacteroidetes, whereas Nitrospirae decrease simultaneously (Supplementary Figure 2). Considering total cell counts, microbial community distribution can be compared in EAA, whereby increasing phyla show a much larger impact due to increase in cell counts on May 3 and decrease of phyla diminishes, respectively (Figure 4).

Based on the outcomes of DAtest (Supplementary Figures 3, 4) a differential abundance testing of phyla between April 7 and May 3 in wells $1-3$ (paired testing using wells) was conducted. The comparison of relative abundances based on LIMMA log (Ritchie et al., 2015) shows to be the most conservative with a total of 9 phyla being significantly different $(p<0.05)$. EdgeR quasi likelihood2 (Robinson et al., 2010) and LIMMA voom (Law et al., 2014; Ritchie et al., 2015), which score slightly better in the DAtest analysis, find more significant differences (12 and 11 phyla, respectively). Since the outcomes of DAtest

TABLE 1 | Alpha-diversity parameters and library size among wells.

\begin{tabular}{|c|c|c|c|c|c|c|c|c|c|c|c|c|}
\hline Well & \multicolumn{3}{|l|}{ Shannon } & \multicolumn{3}{|c|}{ Observed richness } & \multicolumn{3}{|c|}{ Pielou's evenness } & \multicolumn{3}{|l|}{ Library size } \\
\hline 1 & $6.70 \pm 0.14$ & 6.84 & 7.10 & $3,329 \pm 1,017$ & 2,277 & 4,306 & $0.87 \pm 0.05$ & 0.82 & 0.92 & $125,761 \pm 71,506$ & 53,917 & 196,925 \\
\hline 2 & $6.99 \pm 0.43$ & 6.51 & 7.34 & $3,460 \pm 938$ & 2,405 & 4,198 & $0.86 \pm 0.06$ & 0.79 & 0.92 & $119,378 \pm 55,911$ & 54,848 & 153,358 \\
\hline 3 & $6.85 \pm 0.50$ & 6.20 & 7.35 & $3,065 \pm 1,255$ & 1,649 & 4,537 & $0.86 \pm 0.07$ & 0.76 & 0.91 & $112,774 \pm 77,875$ & 37,341 & 198,58 \\
\hline 4 & $6.34 \pm 0.77$ & 5.08 & 7.03 & $2,444 \pm 728$ & 1,344 & 3,34 & $0.82 \pm 0.1$ & 0.65 & 0.90 & $124,608 \pm 80,534$ & 34,21 & 241,095 \\
\hline
\end{tabular}

SD, standard deviation; Min, minimum; Max, maximum. 


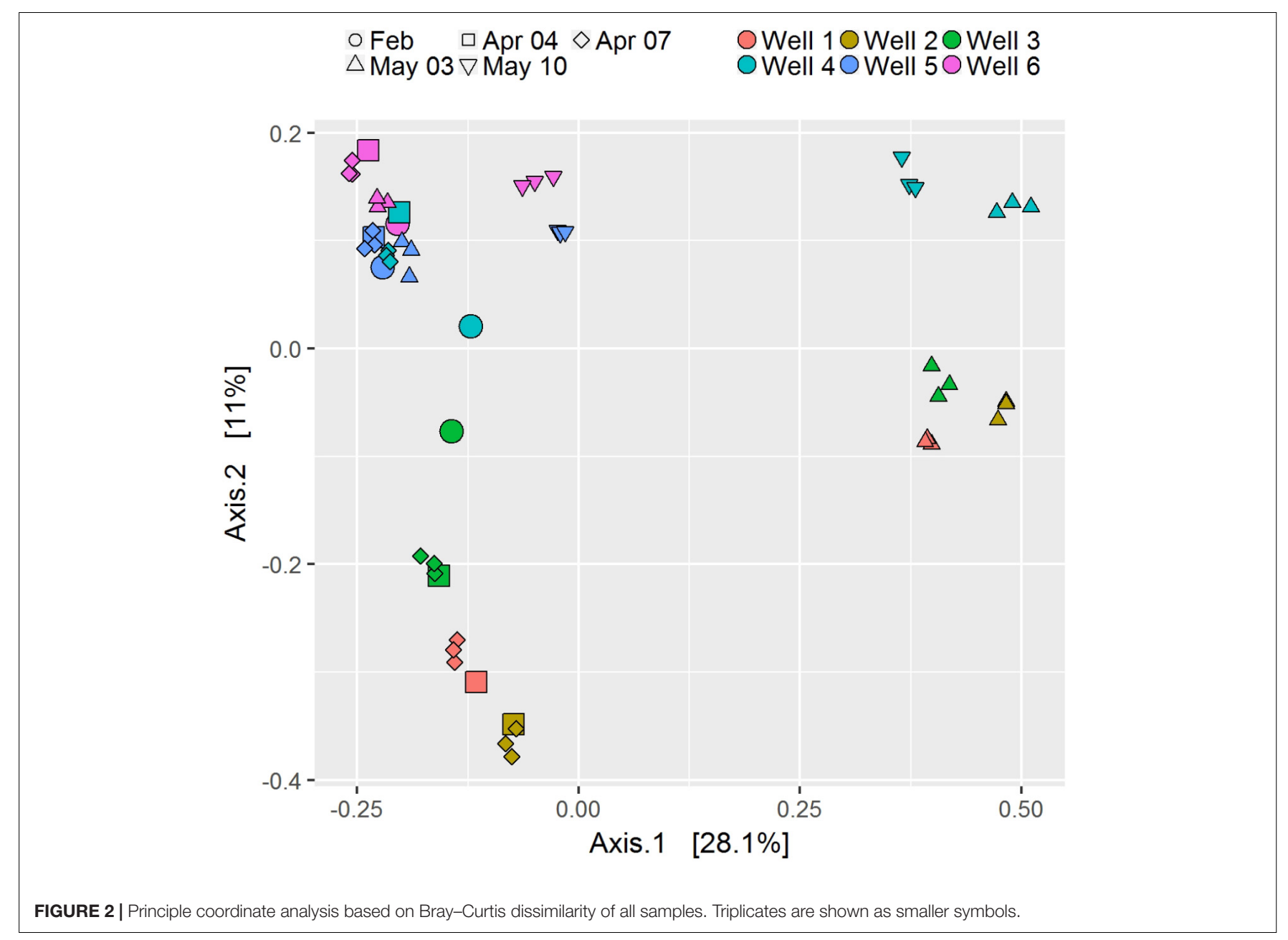

show a considerable increase of false discovery rates (FDR) and false positive rates (FPR) for all the mentioned methods, especially in the case of a high number of spiked features (Supplementary Figure 3), the results must be considered cautiously.

The comparison of EAAs with the best scoring method LIMMA log shows significant differences $(p<0.05)$ for the phyla Actinobacteria, Armatimonadetes, Bacteroidetes, Cyanobacteria, Nitrospinae, Nitrospirae, Planctomycetes and Verrucomicrobia. In contrast to the testing of relative abundances, DAtest does not indicate an increase of FDR and FPR for all settings tested (Supplementary Figure 4).

The significant difference in Armatimonadetes is due to absence of the phylum in April, nevertheless abundances are low in May. The phyla Omnitrophicaeota and Acidobacteria (exception for well 4) seem to decrease when looking at relative abundances. In fact, they proofed to be stable, with little decrease or increase in EAA (Figure 4).

\section{Diversity Patterns Among Families}

The families Verrucomicrobiaceae and Terrimicrobiaceae contribute most to the increase in Verrucomicrobia from April to May, Methylacidiphilaceae is the most abundant family before May and counts remain similar throughout all dates (Figure 5A).

Among Actinobacteria, Sporichthyaceae is the most abundant family before and after the shift, however, overall counts are close to zero in April, suggesting that abundance of the entire phylum develops from surface water entry (Figure 5B).

Proteobacteria show diverse families as well as cell counts in April, which are predominantly replaced by Burkholderiaceae, accounting for most Proteobacteria in May (Figure 5C).

Among the Bacteroidetes, the families Crocinitomicaceae, Flavobacteriaceae and Saprospiraceae contribute exclusively to the phylum, of which Saprosphiraceae rises in May, the others are already abundant before, but to a lesser extent (Figure 5D).

\section{Phylum Based Sample Clustering}

As suggested before, the alignment of samples depending on both dates and wells based on EAA seems obvious (Figure 3). In dependency on relative abundances among all samples, certain groups can also be revealed, which are shown in Figure 6. Between samples, two groups are formed, of which one contains the samples from May 3, wells $1-4$ as well as May 10, well 4. Regarding Phyla, three groups are formed, of which the 


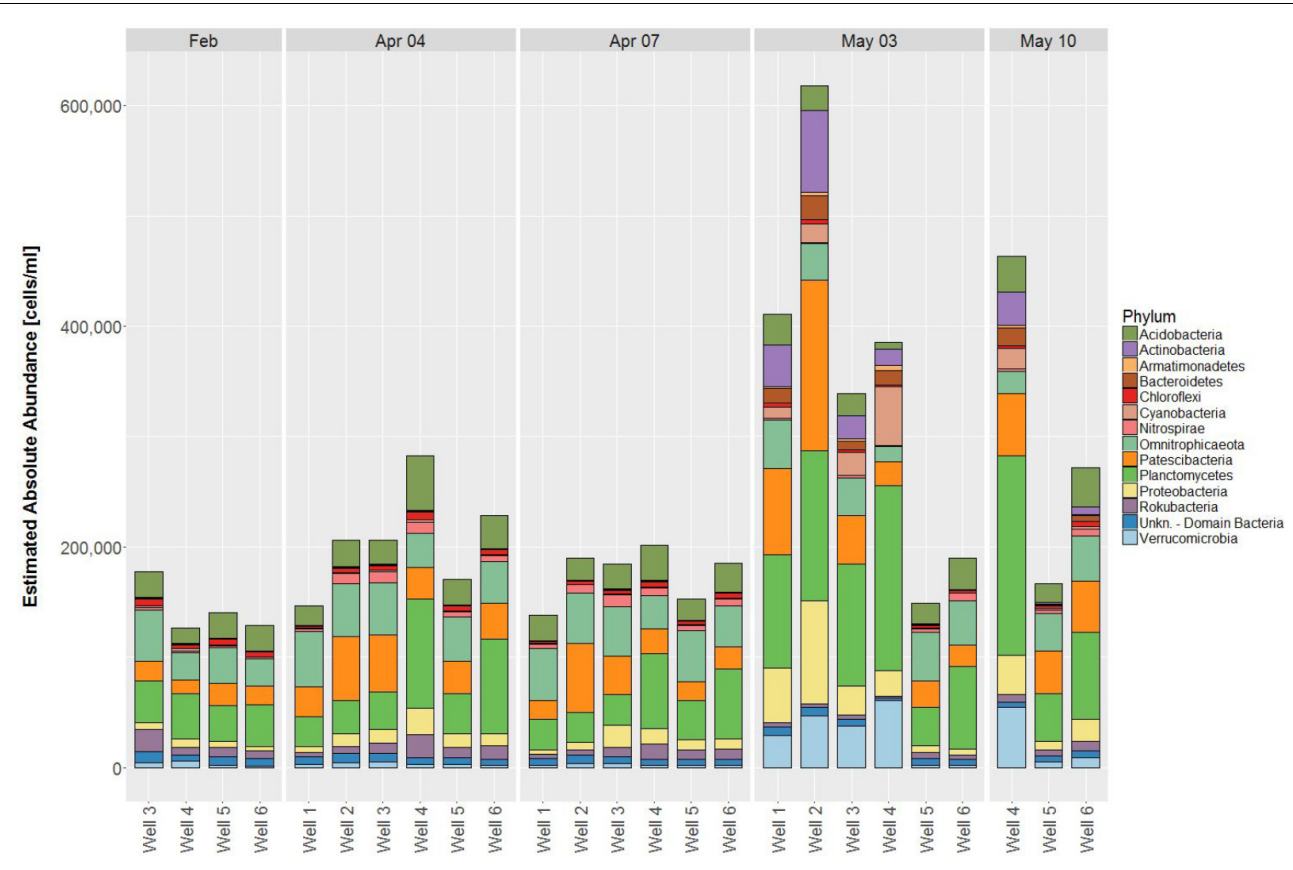

FIGURE 3 | Estimated absolute abundances of phyla at the respective dates (cut-off value 1\%). Reads from triplicate samples were pooled to one sample each.

first contains the four most abundant Phyla (Planctomycetes, Acidobacteria, Omnitrophica, and Patescibacteria), the second contains five Phyla (Proteobacteria, Chloroflexi, Nitrospirae, Rokubacteria, and an unknown bacterium phylum) and the third group contains the four most increasing phyla in May (Verrucomicrobia, Cyanobacteria, Bacteroidetes, and Actinobacteria). Within the second group, Proteobacteria represents the only phylum that remains rather stable between sample groups, whereas all other phyla strongly decrease in May as opposite to group 3, in which phyla increase (Figure 6).

\section{Water Level Differences}

Danube River water levels (measured approx. $3 \mathrm{~km}$ upstream) range from 141 to $145 \mathrm{~m}$ above sealevel. Water levels among wells show high similarity regarding both, overall water levels as well as shifting patterns throughout the investigation period (Figure 7). Two monitoring wells in the backwater show water levels similar to the wells, but are characterized by slightly higher values during intensive abstraction in the wells, when well water levels decrease. In general, Danube, backwater and wells behave similar regarding water level shifts. A major difference between wells and Danube River develops during constant surface water levels over a stable period from end of March until end of April and simultaneous high water abstraction in the wells (Figure 7). Microbial community shifts indicate this period to be decisive for changing water compositions in wells $1-4$. The investigated flood event on May 10 did not affect microbial communities immediately. Comparison of beta diversity between May 3 and May 10 in wells $4-6$ was not significant (PERMANOVA $p>0.05)$.

\section{Abiotic Factors}

It situ parameters have been measured during sampling (Supplementary Figures 5, 6). Noticeable is the electrical conductivity that is higher in well 5 as compared to other wells $(846.8 \pm 96.7 \mu \mathrm{S} / \mathrm{cm}$ in well 5 and $572.8 \pm 57.3 \mu \mathrm{S} / \mathrm{cm}$ in all other wells, received from sampling dates April 7 and May 3). Conductivity in the Danube River and the backwater are lower with $445.5 \pm 23.6 \mu \mathrm{S} / \mathrm{cm}$ and $430.8 \pm 8.6 \mu \mathrm{S} / \mathrm{cm}$, respectively.

\section{DISCUSSION}

The Donau-Auen National Park is characterized by small-scale natural heterogeneity due to former floods and rearrangements. Great differences in permeability, organic matter content and composition of the soil can influence subsequent groundwater characteristics. To investigate small-scale spatial as well as temporal changes, the microbial community patterns of 6 wells in a well field characterized by groundwater influenced by river bank filtration were investigated to reveal information about changes in microbial communities among wells. With such information at hand, conclusions can be drawn on the different impact of surface water on the well water and how this might contribute to optimized subsequent drinking water treatment.

\section{Triplicate Sampling}

Cao et al. (2002) suggests the use of autosimilarity (average similarity among replicates) as a standardization method rather than sample size, as total taxon richness can vary across sampling sites. Therefore, standardized sample size is biased for compositional comparisons and ignores how complete 


\section{Fold changes of EAA}

May 03 relative to Apr 07

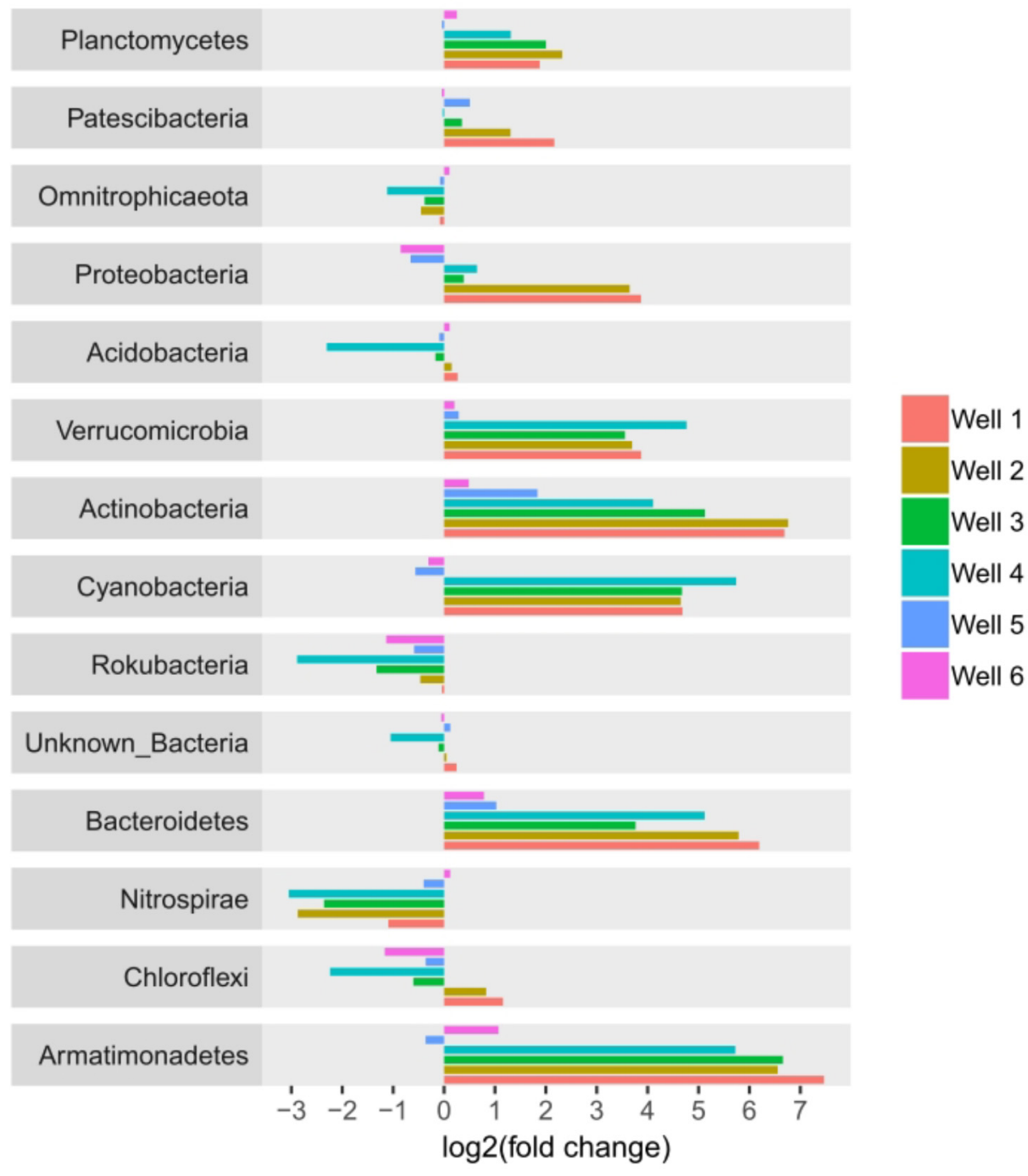

FIGURE 4 | Fold-change plot of phyla from April 7 to May 3 based on estimated absolute abundances (EAA).

communities are represented. The application of replicate samples instead can be used as a measure of sample community representativeness and provides an accurate predictor of richness. Furthermore, Wen et al. (2017) showed that community variation is larger for biological triplicates (i.e., triplicate sampling and subsequent separate preparation) than for technical triplicates (one sample, triplicate amplification). Both increase sampling effort and enhance reproducibility. Additionally, triplicate sampling provides a comparison of variety measurements of different, but still similar samples, thus allowing to discriminate between them.

The similarity within triplicates based on both, Bray-Curtis dissimilarity as well as low variation coefficients (alpha-diversity) shows that the sampling method reveals reliable results. Due to varying read counts among triplicates, which are shown in library size variations, observed richness parameters vary stronger than Shannon-diversity and Pielou's evenness indices. Overall high read counts add confidence to reliable, high quality results, although high rejection rates of reads (57\%) as a consequence of high stringency quality filtering decrease library size. Pooling of multiple libraries increases sequencing depth and consequently generates profound information on microbial communities (Zaheer et al., 2018), thus suggesting that triplicate sampling increases overall richness due to increase in library size and provides an important tool as proof of reproducibility. Furthermore, high sample volumes of $5 \mathrm{~L}$ account for less sequence variation (Staley et al., 2013). With decreasing costs in massive parallel sequencing technologies, we suggest replicate sampling (duplicates or triplicates) to become a basic requirement in future investigations. 

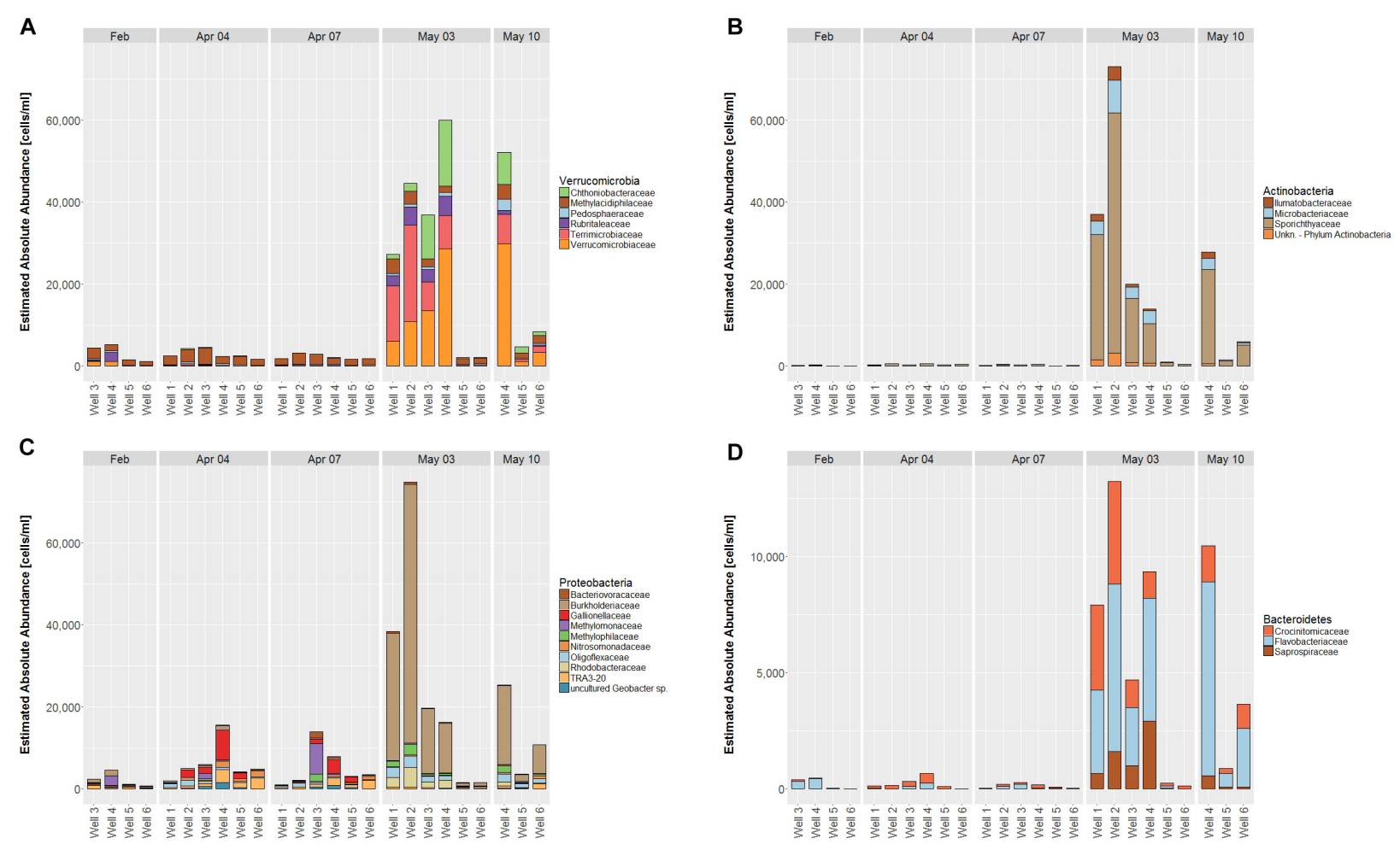

FIGURE 5 | Estimated absolute abundance on family levels (cut-off value 0.5\%) for the Phyla Verrucomicrobia (A), Actinobacteria (B), Proteobacteria (C), and Bacteroidetes (D). Due to lower abundance, $y$-axis scaling is smaller for $\mathbf{D}$ than for $\mathbf{A}-\mathbf{C}$.

\section{Spatial and Temporal Variability}

The microbial community composition of well 5 shows to be stable throughout the investigation period. A steady diversity index together with constant cell counts indicates little influence of surface water microorganisms. Contamination is likely to decrease species richness, thus high diversity parameters can indicate environmental quality (Covich et al., 2004). As this well is located further away from the alluvial surface water than others, it is most likely that increased distance prolongs filtration processes of surface water, leading to decreased influence of allochthonous organisms in well water (Hiscock and Grischek, 2002). These results are in accordance with the findings from Lee et al. (2018) who showed microbial community shifts in groundwater closer to the adjacent stream rather than in those parts with some distance from stream water. Furthermore, due to hydrological conditions, local groundwater recharge might contribute more strongly to the microbial and chemical composition of this well (Hoehn and Scholtis, 2011), thus minimizing inflow of surface water at this point. The latter is supported by an elevated electrical conductivity as compared to other wells, as in many cases groundwater is characterized by a higher mineral content than surface water (Sheets et al., 2002).

In contrast to that, well 4 shows a strong influence induced by temporal variation, leading to major shifts in diversity parameters from April 7 to May 3. Increased cell counts suggest that allochthonous microorganisms strongly affect microbial community compositions in abstraction wells due to reduced interstitial residence time of surface water, which is known to be a critical factor in terms of allochthonous microbial loads (Hiscock and Grischek, 2002).

\section{Estimated Absolute Abundance (EAA)}

Absolute quantification of relative abundances gives a surplus value on the generated information on microbial dynamics such that conclusions can be drawn on actual shifts in microbial populations (Props et al., 2017). In general, mixing surface water with groundwater does increase cell counts due to cell introduction from surface water, the stimulation of heterotrophic respiration, as well as altered organic carbon compositions and is therefore used to monitor microbial dynamics (Stegen et al., 2016; Epting et al., 2018; van Driezum et al., 2018). The impression of suppressing microbial phyla due to the increase of others suggests that allochthonous microorganisms inhabit ecological niches instead of autochthonous ones (Props et al., 2017). Our results emphasize that with the infiltration of surface water rather new niches are created giving rise to changing microbial groups. This assumption is encouraged by the fact that microbial metabolic limitations are overcome by mixing of waters (Stegen et al., 2016) leading to elevated abundances of microbial taxa and that allochthonous contaminations occur temporarily and are unlikely to persist (Pronk et al., 2009). However, on family level diverse shifting patterns within phyla are observed: 


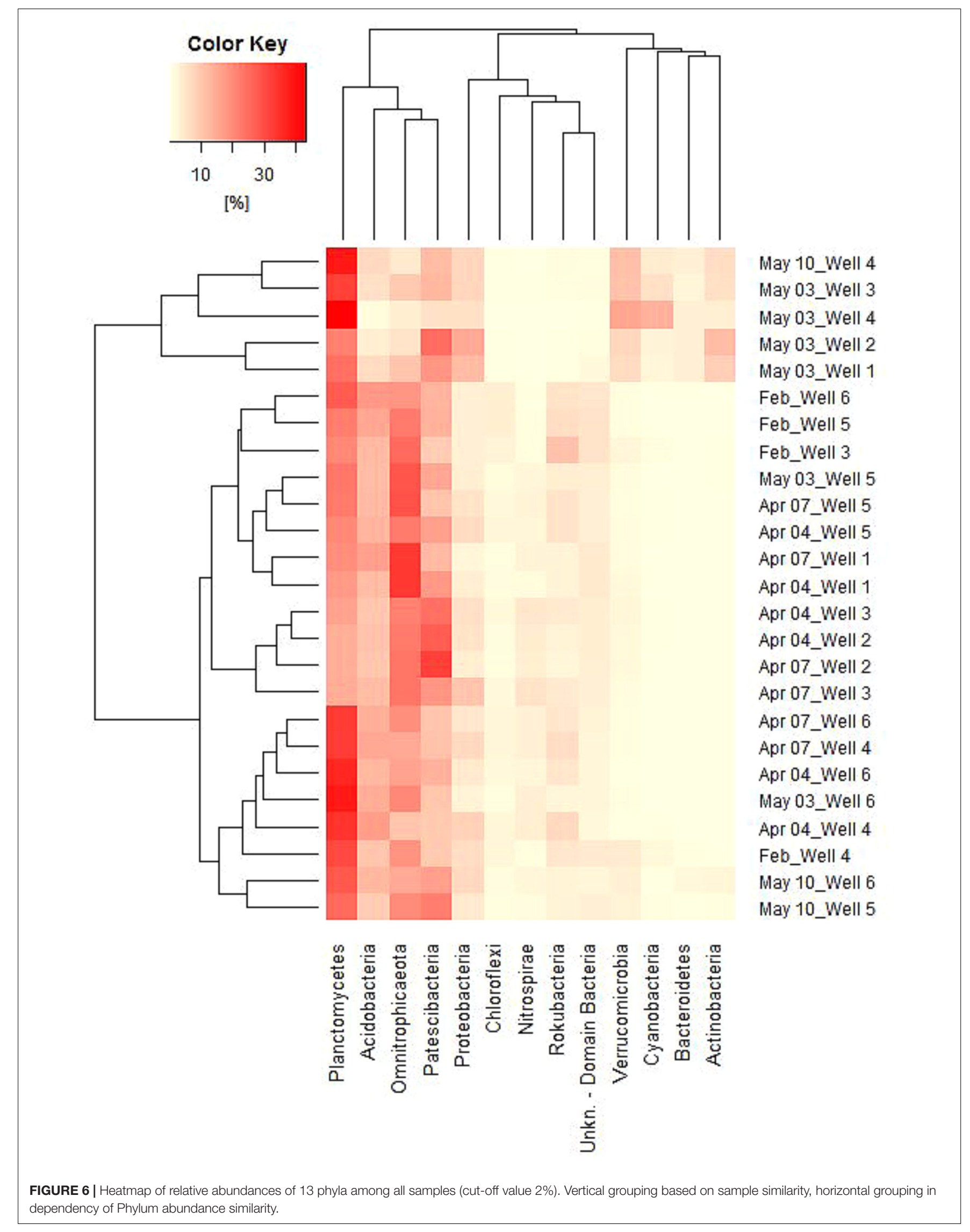




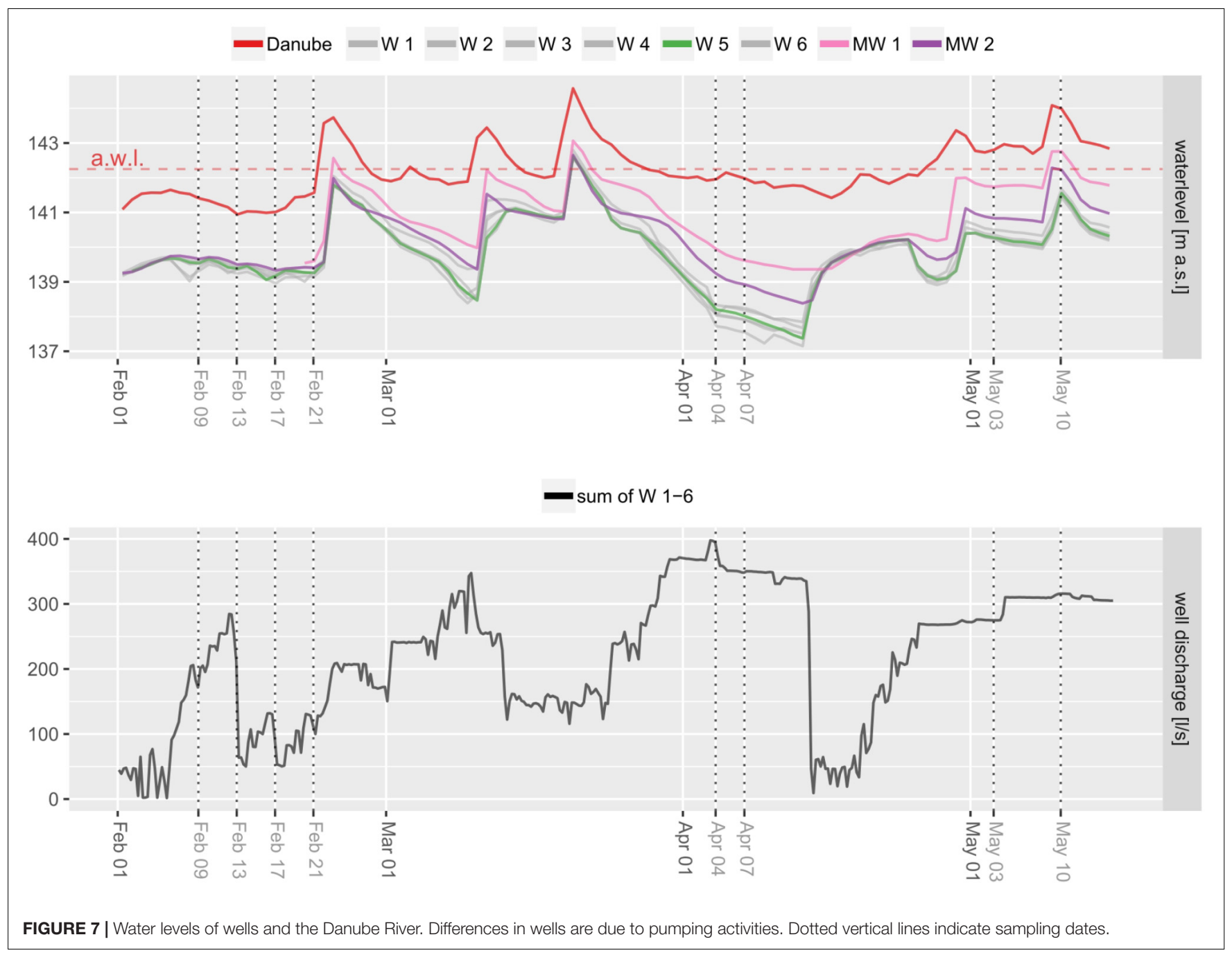

(i) consistent families and rise of new ones (Verrucomicrobia), (ii) increase of existing families (Bacteroidetes), (iii) suppression of families in favor of others (Proteobacteria), and (iv) new development with no or very little previous abundance of the overall phylum (Actinobacteria and Armatimonadetes). The differences in phylum and family shifting patterns indicate that phylogenetic similarity among bacterial groups can lead to replacement of organisms in certain niches, possibly due to functional similarities (Petchey and Gaston, 2006).

\section{Microbial Shifting Patterns}

Our investigations suggest that impacts on microbial communities after a flood event or increased water abstraction in wells do not occur immediately, but after a certain period of time. The combination of increased surface water levels and decreased well water levels results in a higher probability of shifting microbial communities. Most likely, not so much the increase of water level differences, but rather the changes in differences due to abstraction regimes contribute to different water compositions. These findings are in accordance with results from Ascott et al. (2016), who observed rapid recovery of water quality with increased abstraction rates and slower recoveries due to temporary reductions in abstraction rates after extreme flooding. Nevertheless, the delay in microbial shifts may be a result of residence time of water in the subsurface area. Therefore, major shifts in microbial community compositions from April to May during this study may derive from diverse abstraction regimes together with previous rainfalls, but dynamic hydraulic conditions in the river bed make predictions on time shifts difficult (Hiscock and Grischek, 2002). The immediate investigation of a flood event in May did not show major shifts in community compositions, although well 6 shows slight changes toward community compositions of wells $1-4$, giving rise to expect similar dynamics in this well as a consequence of proceeding rain events and hydraulic differences.

\section{Taxonomy}

The overall findings of taxonomic groups are in accordance with other data: Graham et al. (2017) compared microbial communities of Inland, Nearshore and River water. All of 
the ten most abundant phyla of each sample group were also identified in our investigation, additionally we found the phyla Rokubacteria and Patescibacteria. The shifts from our results are roughly in accordance with their findings in River water as compared to Inland and Nearshore samples, respectively: Bacteroidetes, Actinobacteria and Verrucomicrobia are together with Proteobacteria among the most abundant phyla in River water samples, Armatimonadetes only occur in River samples and Cyanobacteria that are not abundant in Inland samples and little abundant in Nearshore samples show abundancies of $4.66 \%$ in River samples. Findings from Lee et al. (2018) show similar results. In our study, the four strongest increasing phyla, i.e., Verrucomicrobia, Actinobacteria, Cyanobacteria, and Bacteroidetes, are all considered typical freshwater bacteria (Newton et al., 2011) and have also been found previously in freshwater by Iliev et al. (2017) and Kim et al. (2018) and others. Patescibacteria were first reported in groundwater and sediments of anoxic environments (Elshahed et al., 2005; Youssef et al., 2011; Wrighton et al., 2012), but showed to be widespread in most semiaquatic habitats (Sánchez-Osuna et al., 2017). Rokubacteria, also found in groundwater samples, are most closely related to the phylum Nitrospira. They are characterized by a high level of genetic heterogeneity and show potential for a versatile, mixotrophic metabolism. Nevertheless, they are rather low in abundance at different sites, possibly explaining the lack of identification in other studies (Becraft et al., 2017).

Actinobacteria are abundant in rivers (Zwart et al., 2002), although the family Sporichthyaceae, which contributes most to the increase in Actinobacteria has been found in soils (Tamura, 2014), suggesting that entry occurs via the subsurface area rather than surface water itself. Typically, Actinobacteria are very small $\left(<0.1 \mu \mathrm{m}^{3}\right)$, free living cells (Hahn et al., 2003). In contrast, Bacteroidetes are mainly particle associated and strongly dependent on the availability of organic matter (Newton et al., 2011). They are able to digest large organic polymers (Gómez-Pereira et al., 2010; McBride, 2014) and the most abundant family among freshwaters representing Flavobacteriaceae (GómezPereira et al., 2010) was also found in our investigations. Cyanobacteria are associated with algal blooms in surface water (Berry et al., 2017) and may produce toxins that affect drinking water quality (Walter et al., 2018). Due to their dependency on a light source, increase happens due to intrusion rather than growth and persistence is very unlikely. The abundance of Verrucomicrobia has been underestimated in the past due to poor primer coverage (Bergmann et al., 2011). However, they are present in soil and freshwater habitats accounting for up to $42 \%$ in lake samples (Chiang et al., 2018). All Verrucomicrobia families found during this investigation were also abundant elsewhere in river water (Balmonte et al., 2016). They show diverse metabolic capabilities among clades (Chiang et al., 2018), suggesting a high versatility and capability of persisting different environmental conditions.

Heatmap grouping results underline the existence of well adapted autochthonous microbial populations and typical shifts from one composition to another as a consequence of allochthonous microbial influences, as it was previously suggested by Danielopol et al. (2003) and Griebler and Lueders (2009) and others. The similarity among samples at the beginning of the investigation and subsequent divergence of well microbial characteristics point to the cumulative outcome of diverse biotic and abiotic impacts leading to differences in well water characteristics.

\section{Practical Implications}

The occurrence of surface-groundwater mixes is subject to temporally dynamic and spatially complex processes, making predictions among them difficult (Stegen et al., 2016). The concept of detecting mixtures of surface water and groundwater via microorganism shifts rather than studying distribution patterns of water types within the passage through the subsurface area can provide adequate statements about mixing patterns in the alluvial groundwater. Up to now, no consensus exists about typical pristine groundwater bacteria (Pernthaler, 2013) and legislations lack microbial parameters as indicators of groundwater quality (European Commission, 2000), thus no definition of "good" microbial groundwater quality exists. Our results give a comprehensive insight into microbial communities from a river bank filtrate used for drinking water and allow for conclusions on the spatial distribution of bank filtrated surface water among wells. Identified microbial dynamics in dependency of water levels resulting from both rain events as well as varying pumping rates can be indicative regarding the improvement of a constant overall microbial water composition in the subsequent drinking water distribution system. Additional microbial investigations of river water could determine the origin of allochthonous microorganisms as it was performed by Kim et al. (2018) and Lee et al. (2018). Furthermore, abiotic factors are required to better understand the mechanisms of changing water qualities. Adapting operational regimes based on the revealed information about microbial shifts together with abiotic parameters, such as electrical conductivity, oxygen content and temperature, shows potential to maintain a microbiologically stable raw water and thus minimizes the risks of unexpected technical as well as hygienic disturbances. It is known that allochthonous contaminations as a consequence of increased water levels and shortened residence time in the river bank are unlikely to persist in the groundwater (Pronk et al., 2009). Nevertheless, a large proportion of VBNC microorganisms give rise for monitoring microbial community compositions in abstraction wells (Ramamurthy et al., 2014). In order to determine how long communities will need to return to their initial conditions and what factors influence the recovery (Ascott et al., 2016), investigations implemented on a longer time-span are required. Furthermore, online monitoring of cell counts in wells can indicate adequate timing of sampling for sequencing analyses, as suggested by Besmer et al. (2016). Although the dynamics in microbial community compositions outline water mixture patterns, the consequences introduced microorganisms might have on water regarding downstream drinking water treatment and distribution are widely unknown and need to be further investigated. 


\section{DATA AVAILABILITY STATEMENT}

The dataset analyzed for this study can be found in the European Nucleotide Archive (ENA) under the accession number PRJEB28172. The flow cytometry data can be found on the flowrepository database (https://flowrepository.org) under the ID number FR-FCM-ZYRK. The analysis pipeline is available on github under the repository link (chrischoen/r.riverbankfiltrate).

\section{AUTHOR CONTRIBUTIONS}

CF carried out sample collecting, laboratory work, data analysis, and drafted the manuscript. CS, PP, and DK implemented data analyses and helped to draft the manuscript. EM, MZ-P, and RP conceived the study and revised the paper. KD provided facilities

\section{REFERENCES}

Anderson, M. J. (2008). A new method for non-parametric multivariate analysis of variance. Austral Ecol. 26, 32-46. doi: 10.1046/j.1442-9993.2001.01070.x

Ascott, M. J., Lapworth, D. J., Gooddy, D. C., Sage, R. C., and Karapanos, I. (2016). Impacts of extreme flooding on riverbank filtration water quality. Sci. Total Environ. 55, 89-101. doi: 10.1016/j.scitotenv.2016.02.169

Balmonte, J. P., Arnosti, C., Underwood, S., McKee, B. A., and Teske, A. (2016). Riverine bacterial communities reveal environmental disturbance signatures within the Betaproteobacteria and Verrucomicrobia. Front. Microbiol. 7:1441. doi: 10.3389/fmicb.2016.01441

Becraft, E. D., Woyke, T., Jarett, J., Ivanova, N., Godoy-Vitorino, F., Poulton, N., et al. (2017). Rokubacteria: genomic giants among the uncultured bacterial phyla. Front. Microbiol. 8:2264. doi: 10.3389/fmicb.2017.02264

Bergmann, G. T., Bates, S. T., Eilers, K. G., Lauber, C. L., Caporaso, J. G., Walters, W. A., et al. (2011). The under-recognized dominance of Verrucomicrobia in soil bacterial communities. Soil Biol. Biochem. 43, 1450-1455. doi: 10.1016/j. soilbio.2011.03.012

Berry, M. A., Davis, T. W., Cory, R. M., Duhaime, M. B., Johengen, T. H., Kling, G. W., et al. (2017). Cyanobacterial harmful algal blooms are a biological disturbance to Western Lake Erie bacterial communities. Environ. Microbiol. 19, 1149-1162. doi: 10.1111/1462-2920.13640

Besmer, M. D., Epting, J., Page, R. M., Sigrist, J. A., Huggenberger, P., and Hammes, F. (2016). Online flow cytometry reveals microbial dynamics influenced by concurrent natural and operational events in groundwater used for drinking water treatment. Sci. Rep. 6:38462. doi: 10.1038/srep3 8462

Besmer, M. D., Hammes, F., Sigrist, J. A., and Ort, C. (2017). Evaluating monitoring strategies to detect precipitation-induced microbial contamination events in karstic springs used for drinking water. Front. Microbiol. 8:2229. doi: 10.3389/ fmicb.2017.02229

Boulton, A. J., Findlay, S., Marmonier, P., Stanley, E. H., and Valett, H. M. (1998). The functional significance of the hyporheic zone in streams and rivers. Annu. Rev. Ecol. Syst. 29, 59-81. doi: 10.1146/annurev.ecolsys.29.1.59

Bredenhann, L., and Braune, E. (2000). Policy and Strategy for Groundwater Quality Management in South Africa, 1st Edn. Pretoria: Department of Water Affairs and Forestry Private.

Callahan, B. J., McMurdie, P. J., Rosen, M. J., Han, A. W., Johnson, A. J., and Holmes, S. P. (2016). DADA2: High-resolution sample inference from Illumina amplicon data. Nat. Methods 13, 581-583. doi: 10.1038/nmeth.3869

Cao, Y., Williams, D. D., and Larsen, D. P. (2002). Comparison of ecological communities: the problem of sample representativeness. Ecol. Monogr. 72, 41-56. doi: 10.1890/0012-9615(2002)072[0041:COECTP]2.0.CO;2

Chiang, E., Schmidt, M. L., Berry, M. A., Biddanda, B. A., Burtner, A., Johengen, T. H., et al. (2018). Verrucomicrobia are prevalent in north-temperate freshwater lakes and display class-level preferences between lake habitats. PLoS One 13:e0195112. doi: 10.1371/journal.pone.0195112 and helped implementing the laboratory work. All authors have approved the submission of the article.

\section{FUNDING}

We thank the Bundesministerium für Nachhaltigkeit und Tourismus, Austria and the ÖVGW (Austrian Gas and Water Association) for the financial support.

\section{SUPPLEMENTARY MATERIAL}

The Supplementary Material for this article can be found online at: https://www.frontiersin.org/articles/10.3389/fmicb. 2018.02887/full\#supplementary-material

Covich, A. P., Austen, M. C., Bärlocher, F., Chauvet, E., Cardinale, B. J., Biles, C. L., et al. (2004). The role of biodiversity in the functioning of freshwater and marine benthic ecosystems. BioScience 54, 767-775. doi: 10.1641/00063568(2004)054[0767:TROBIT]2.0.CO;2

Danielopol, D. L., Griebler, C., Gunatilaka, A., and Notenboom, J. (2003). Present state and future prospects for groundwater ecosystems. Environ. Conserv. 30, 104-130. doi: 10.1017/S0376892903000109

Elshahed, M. S., Najar, F. Z., Aycock, M., Qu, C., Roe, B. A., and Krumholz, L. R. (2005). Metagenomic analysis of the microbial community at Zodletone Spring (Oklahoma): insights into the genome of a member of the novel candidate division OD1. Appl. Environ. Microbiol. 71, 7598-7602. doi: 10.1128/AEM.71. 11.7598-7602.2005

Epting, J., Huggenberger, P., Radny, D., Hammes, F., Hollender, J., Page, R. M., et al. (2018). Spatiotemporal scales of river-groundwater interaction - The role of local interaction processes and regional groundwater regimes. Sci. Total Environ. 618, 1224-1243. doi: 10.1016/j.scitotenv.2017.09.219

European Commission (2000). Directive 2000/60/EC of the European Parliament and of the Council of 23 October 2000 Establishing a Framework for Community action in the Field of Water Policy. Brussels: European Commission.

Ge, Y., and Yu, S. (2017). Next-generation sequencing for investigating the diversity of microorganisms and pathogenic bacteria in a water source. Trop. J. Pharm. Res. 16, 1503-1512. doi: 10.4314/tjpr.v16i7.7

Getches, D. H. (1989). Groundwater quality protection: setting a national goal for state and federal programs. Chi Kent L Rev. 65:387.

Gómez-Pereira, P. R., Fuchs, B. M., Alonso, C., Oliver, M. J., Van Beusekom, J. E., and Amann, R. (2010). Distinct flavobacterial communities in contrasting water masses of the North Atlantic Ocean. ISME J. 4, 472-487. doi: 10.1038/ismej. 2009.142

Graham, E. B., Crump, A. R., Resch, C. T., Fansler, S., Arntzen, E., Kennedy, D. W., et al. (2017). Deterministic influences exceed dispersal effects on hydrologicallyconnected microbiomes. Environ. Microbiol. 19, 1552-1567. doi: 10.1111/14622920.13720

Griebler, C., and Lueders, T. (2009). Microbial biodiversity in groundwater ecosystems. Freshw. Biol. 54, 649-677. doi: 10.1111/j.1365-2427.2008.02013.x

Griebler, C., Malard, F., and Lefébure, T. (2014). Current developments in groundwater ecology-from biodiversity to ecosystem function and services. Curr. Opin. Biotechnol. 27, 159-167. doi: 10.1016/j.copbio.2014.01.018

Hahn, M. W., Lünsdorf, H., Wu, Q., Schauer, M., Höfle, M. G., Boenigk, J., et al. (2003). Isolation of novel ultramicrobacteria classified as Actinobacteria from five freshwater habitats in Europe and Asia. Appl. Environ. Microbiol. 69, 1442-1451. doi: 10.1128/AEM.69.3.1442-1451.2003

Herbold, C. W., Pelikan, C., Kuzyk, O., Hausmann, B., Angel, R., Berry, D., et al. (2015). A flexible and economical barcoding approach for highly multiplexed amplicon sequencing of diverse target genes. Front. Microbiol. 6:731. doi: 10 . 3389/fmicb.2015.00731

Hiscock, K. M., and Grischek, T. (2002). Attenuation of groundwater pollution by bank filtration. J. Hydrol. 266, 139-144. doi: 10.1016/S0022-1694(02)00158-0 
Hoehn, E., and Scholtis, A. (2011). Exchange between a river and groundwater, assessed with hydrochemical data. Hydrol. Earth Syst. Sci. 15, 983-988. doi: 10.5194/hess-15-983-2011

Hou, L., Zhou, Q., Wu, Q., Gu, Q., Sun, M., and Zhang, J. (2018). Spatiotemporal changes in bacterial community and microbial activity in a full-scale drinking water treatment plant. Sci. Total Environ. 625, 449-459. doi: 10.1016/j.scitotenv. 2017.12.301

Hugerth, L. W., and Andersson, A. F. (2017). Analysing microbial community composition through amplicon sequencing: from sampling to hypothesis testing. Front. Microbiol. 8:1561. doi: 10.3389/fmicb.2017.01561

Iliev, I., Yahubyan, G., Marhova, M., Apostolova, E., Gozmanova, M., Gecheva, G., et al. (2017). Metagenomic profiling of the microbial freshwater communities in two Bulgarian reservoirs. J. Basic Microbiol. 57, 669-679. doi: 10.1002/jobm. 201700137

Kaevska, M., Videnska, P., Sedlar, K., and Slana, I. (2016). Seasonal changes in microbial community composition in river water studied using 454pyrosequencing. SpringerPlus 5:409. doi: 10.1186/s40064-016-2043-6

Karczewski, K., Riss, H. W., and Meyer, E. I. (2017). Comparison of DNAfingerprinting (T-RFLP) and high-throughput sequencing (HTS) to assess the diversity and composition of microbial communities in groundwater ecosystems. Limnologica 67, 45-53. doi: 10.1016/j.limno.2017.10.001

Katsanou, K., and Karapanagioti, H. K. (2017). Surface Water and Groundwater Sources for Drinking Water, The Handbook of Environmental Chemistry. Berlin: Springer, 1-19.

Kim, H., Kaown, D., Mayer, B., Lee, J. Y., and Lee, K. K. (2018). Combining pyrosequencing and isotopic approaches to assess denitrification in a hyporheic zone. Sci. Total Environ. 631-632, 755-764. doi: 10.1016/j.scitotenv.2018.03.073

Klindworth, A., Pruesse, E., Schweer, T., Peplies, J., Quast, C., Horn, M., et al. (2013). Evaluation of general 16S ribosomal RNA gene PCR primers for classical and next-generation sequencing-based diversity studies. Nucleic Acids Res. 41:e1. doi: 10.1093/nar/gks808

Law, C. W., Chen, Y., Shi, W., and Smyth, G. K. (2014). voom: precision weights unlock linear model analysis tools for RNA-seq read counts. Genome Biol. 15:R29. doi: 10.1186/gb-2014-15-2-r29

Lee, J.-H., Lee, B.-J., and Unno, T. (2018). Bacterial communities in groundand surface water mixing zone induced by seasonal heavy extraction of groundwater. Geomicrobiol. J. 35, 768-774. doi: 10.1080/01490451.2018. 1468834

Li, X. X., Liu, J. F., Zhou, L., Mbadinga, S. M., Yang, S. Z., Gu, J. D., et al. (2017). Diversity and composition of sulfate-reducing microbial communities based on genomic DNA and RNA transcription in production water of high temperature and corrosive oil reservoir. Front. Microbiol. 8:1011. doi: 10.3389/fmicb.2017. 01011

Liao, H., Chapman, S. J., Li, Y., and Yao, H. (2018). Dynamics of microbial biomass and community composition after short-term water status change in Chinese paddy soils. Environ. Sci. Pollut. Res. 25, 2932-2941. doi: 10.1007/s11356-0170690-y

Lin, X., McKinley, J., Resch, C. T., Kaluzny, R., Lauber, C. L., Fredrickson, J., et al. (2012). Spatial and temporal dynamics of the microbial community in the Hanford unconfined aquifer. ISME J. 6, 1665-1676. doi: 10.1038/ismej.2012.26

McBride, M. J. (2014). “The family flavobacteriaceae," in The Prokaryotes: Other Major Lineages of Bacteria and The Archaea, eds E. Rosenberg, E. F. DeLong, S. Lory, E. Stackebrandt, and E. Thompson (Berlin: Spriger), 643-676.

McMurdie, P. J., and Holmes, S. (2013). Phyloseq: an r package for reproducible interactive analysis and graphics of microbiome census data. PLoS One 8:e61217. doi: 10.1371/journal.pone.0061217

Newton, R. J., Jones, S. E., Eiler, A., McMahon, K. D., and Bertilsson, S. (2011). A guide to the natural history of freshwater lake bacteria. Microbiol. Mol. Biol. Rev. 75, 14-49. doi: 10.1128/MMBR.00028-10

Oksanen, J., Guillaume Blanchet, F., Friendly, M., Kindt, R., Legendre, P., McGlin, D., et al. (2018). vegan: Community Ecology Package. R package version 2.5-2. Available at: https://rdrr.io/cran/vegan/

Pedersen, K. (2000). Exploration of deep intraterrestrial microbial life: current perspectives. FEMS Microbiol. Lett. 185, 9-16. doi: 10.1111/j.1574-6968.2000. tb09033.x

Pernthaler, J. (2013). "Freshwater microbial communities," in The Prokaryotes: Prokaryotic Communities and Ecophysiology, eds E. Rosenberg, E. F. DeLong, S. Lory, E. Stackebrandt, and F. Thompson (Berlin: Springer), 97-112.
Petchey, O. L., and Gaston, K. J. (2006). Functional diversity: back to basics and looking forward. Ecol. Lett. 9, 741-758. doi: 10.1111/j.1461-0248.2006.00924.x

Pronk, M., Goldscheider, N., and Zopfi, J. (2009). Microbial communities in karst groundwater and their potential use for biomonitoring. Hydrogeol. J. 17, 37-48. doi: 10.1007/s10040-008-0350-x

Props, R., Kerckhof, F. M., Rubbens, P., Vrieze, J. D., Sanabria, E. H., Waegeman, W., et al. (2017). Absolute quantification of microbial taxon abundances. ISME J. 11, 584-587. doi: 10.1038/ismej.2016.117

Raes, J., and Bork, P. (2008). Molecular eco-systems biology: towards an understanding of community function. Nat. Rev. Microbiol. 6, 693-699. doi: 10.1038/nrmicro1935

Ramamurthy, T., Ghosh, A., Pazhani, G. P., and Shinoda, S. (2014). Current perspectives on viable but non-culturable (VBNC) pathogenic bacteria. Front. Public Health 2:103. doi: 10.3389/fpubh.2014.00103

Rappé, M. S., and Giovannoni, S. J. (2003). The uncultured microbial majority. Annu. Rev. Microbiol. 57, 369-394. doi: 10.1146/annurev.micro.57.030502. 090759

Ray, C., Soong, T. W., Lian, Y. Q., and Roadcap, G. S. (2002). Effect of floodinduced chemical load on filtrate quality at bank filtration sites. J. Hydrol. 266, 235-258. doi: 10.1016/S0022-1694(02)00168-3

Ritchie, M. E., Phipson, B., Wu, D., Hu, Y., Law, C. W., Shi, W., et al. (2015). limma powers differential expression analyses for RNA-sequencing and microarray studies. Nucleic Acids Res. 43:e47. doi: 10.1093/nar/ gkv007

Robasky, K., Lewis, N. E., and Church, G. M. (2014). The role of replicates for error mitigation in next-generation sequencing. Nat. Rev. Genet. 15, 56-62. doi: $10.1038 / \mathrm{nrg} 3655$

Robinson, M. D., McCarthy, D. J., and Smyth, G. K. (2010). edgeR: a Bioconductor package for differential expression analysis of digital gene expression data. Bioinformatics 26, 139-140. doi: 10.1093/bioinformatics/ btp616

Romera-Castillo, C., Pinto, M., Langer, T. M., Álvarez-Salgado, X. A., and Herndl, G. J. (2018). Dissolved organic carbon leaching from plastics stimulates microbial activity in the ocean. Nat. Commun. 9:1430. doi: 10.1038/s41467-01803798-5

Roszak, D. B., and Colwell, R. R. (1987). Survival strategies of bacteria in the natural environment. Microbiol. Rev. 51, 365-379.

Russel, J., Thorsen, J., Brejnrod, A. D., Bisgaard, H., Sorensen, S. J., and Burmolle, M. (2018). DAtest: a framework for choosing differential abundance or expression method. bioRxiv [Preprint]. doi: 10.1101/241802

Sánchez-Osuna, M., Barbé, J., and Erill, I. (2017). Comparative genomics of the DNA damage-inducible network in the Patescibacteria. Environ. Microbiol. 19, 3465-3474. doi: 10.1111/1462-2920.13826

Schwab, V. F., Herrmann, M., Roth, V. N., Gleixner, G., Lehmann, R., Pohnert, G., et al. (2017). Functional diversity of microbial communities in pristine aquifers inferred by PLFA- and sequencing-based approaches. Biogeosciences 14, 2697 2714. doi: 10.5194/bg-14-2697-2017

Sheets, R. A., Darner, R. A., and Whitteberry, B. L. (2002). Lag times of bank filtration at a well field, Cincinnati, Ohio, USA. J. Hydrol. 266, 162-174. doi: 10.1016/S0022-1694(02)00164-6

Sprenger, C., Lorenzen, G., Hülshoff, I., Grützmacher, G., Ronghang, M., and Pekdeger, A. (2011). Vulnerability of bank filtration systems to climate change. Sci. Total Environ. 409, 655-663. doi: 10.1016/j.scitotenv.2010.11.002

Staley, C., Gould, T. J., Wang, P., Phillips, J., Cotner, J. B., and Sadowsky, M. J. (2015). Evaluation of water sampling methodologies for amplicon-based characterization of bacterial community structure. J. Microbiol. Methods 114, 43-50. doi: 10.1016/j.mimet.2015.05.003

Staley, C., Unno, T., Gould, T. J., Jarvis, B., Phillips, J., Cotner, J. B., et al. (2013). Application of Illumina next-generation sequencing to characterize the bacterial community of the Upper Mississippi River. J. Appl. Microbiol. 115, 1147-1158. doi: 10.1111/jam.12323

Stegen, J. C., Fredrickson, J. K., Wilkins, M. J., Konopka, A. E., Nelson, W. C., Arntzen, E. V., et al. (2016). Groundwater-surface water mixing shifts ecological assembly processes and stimulates organic carbon turnover. Nat. Commun. 7:11237. doi: $10.1038 /$ ncomms 11237

Tamura, T. (2014). "The family sporichthyaceae," in The Prokaryotes: Actinobacteria, eds E. Rosenberg, E. F. DeLong, S. Lory, E. Stackebrandt, and F. Thompson (Berlin: Springer), 883-888. 
van Dijk, E. L., Auger, H., Jaszczyszyn, Y., and Thermes, C. (2014). Ten years of next-generation sequencing technology. Trends Genet. 30, 418-426. doi: 10.1016/j.tig.2014.07.001

van Driezum, I. H., Chik, A. H. S., Jakwerth, S., Lindner, G., Farnleitner, A. H., Sommer, R., et al. (2018). Spatiotemporal analysis of bacterial biomass and activity to understand surface and groundwater interactions in a highly dynamic riverbank filtration system. Sci. Total Environ. 627, 450-461. doi: 10.1016/j.scitotenv.2018.01.226

Van Nevel, S., Koetzsch, S., Proctor, C. R., Besmer, M. D., Prest, E. I., Vrouwenvelder, J. S., et al. (2017). Flow cytometric bacterial cell counts challenge conventional heterotrophic plate counts for routine microbiological drinking water monitoring. Water Res. 113, 191-206. doi: 10.1016/j.watres. 2017.01.065

Vivien, R., Lejzerowicz, F., and Pawlowski, J. (2016). Next-generation sequencing of aquatic oligochaetes: comparison of experimental communities. PLoS One 11:e0148644. doi: 10.1371/journal.pone.0148644

Walter, J. M., Lopes, F. A. C., Lopes-Ferreira, M., Vidal, L. M., Leomil, L., Melo, F., et al. (2018). Occurrence of harmful cyanobacteria in drinking water from a severely drought-impacted semi-arid region. Front. Microbiol. 9:176. doi: 10. 3389/fmicb.2018.00176

Wang, L., Zhang, J., Li, H., Yang, H., Peng, C., Peng, Z., et al. (2018). Shift in the microbial community composition of surface water and sediment along an urban river. Sci. Total Environ. 627, 600-612. doi: 10.1016/j.scitotenv.2018.01.203

Wen, C., Wu, L., Qin, Y., Van Nostrand, J. D., Ning, D., Sun, B., et al. (2017). Evaluation of the reproducibility of amplicon sequencing with Illumina MiSeq platform. PLoS One 12:e0176716. doi: 10.1371/journal.pone.0176716

Wett, B., Jarosch, H., and Ingerle, K. (2002). Flood induced infiltration affecting a bank filtrate well at the River Enns, Austria. J. Hydrol. 266, 222-234. doi: 10.1016/S0022-1694(02)00167-1

Wrighton, K. C., Thomas, B. C., Sharon, I., Miller, C. S., Castelle, C. J., VerBerkmoes, N. C., et al. (2012). Fermentation, hydrogen, and sulfur metabolism in multiple uncultivated bacterial phyla. Science 337, 1661-1665. doi: 10.1126/science.1224041
Youssef, N. H., Blainey, P. C., Quake, S. R., and Elshahed, M. S. (2011). Partial genome assembly for a candidate division OP11 single cell from an anoxic spring (Zodletone Spring. Oklahoma). Appl. Environ. Microbiol. 77, 7804-7814. doi: 10.1128/AEM.06059-11

Zaheer, R., Noyes, N., Ortega Polo, R., Cook, S. R., Marinier, E., Van Domselaar, G., et al. (2018). Impact of sequencing depth on the characterization of the microbiome and resistome. Sci. Rep. 8:5890. doi: 10.1038/s41598-01824280-8

Zhang, Y., Oh, S., and Liu, W. T. (2017). Impact of drinking water treatment and distribution on the microbiome continuum: an ecological disturbance's perspective. Environ. Microbiol. 19, 3163-3174. doi: 10.1111/1462-2920.1 3800

Zhang, Z., Qu, Y., Li, S., Feng, K., Wang, S., Cai, W., et al. (2017). Soil bacterial quantification approaches coupling with relative abundances reflecting the changes of taxa. Sci. Rep. 7:4837. doi: 10.1038/s41598-017-05260-w

Zunabovic-Pichler, M., Mayr, E., Schönher, C., Fiedler, C. J., Kerschbaumer, D., and Perfler, R. (2018). Durchflusszytometrie in der Wasserversorgung. Bundesministerium Nachhaltigkeit Tourismus 157, 35-37.

Zwart, G., Crump, B. C., Kamst-van Agterveld, M. P., Hagen, F., and Han, S. K. (2002). Typical freshwater bacteria: an analysis of available $16 \mathrm{~S}$ rRNA gene sequences from plankton of lakes and rivers. Aquat. Microbiol. Ecol. 28, 141-155. doi: 10.3354/ame028141

Conflict of Interest Statement: The authors declare that the research was conducted in the absence of any commercial or financial relationships that could be construed as a potential conflict of interest.

Copyright (c) 2018 Fiedler, Schönher, Proksch, Kerschbaumer, Mayr, ZunabovicPichler, Domig and Perfler. This is an open-access article distributed under the terms of the Creative Commons Attribution License (CC BY). The use, distribution or reproduction in other forums is permitted, provided the original author(s) and the copyright owner(s) are credited and that the original publication in this journal is cited, in accordance with accepted academic practice. No use, distribution or reproduction is permitted which does not comply with these terms. 